\title{
Robotik Uygulamalar İçin Titreşime Dayalı Hareket Eden Amfibik İlerleme Mekanizması
}

\author{
Ahmed Burak TAPAN ${ }^{* 1}$, Murat REIS ${ }^{2}$ \\ 1,2Bursa Uludağ Üniversitesi, Mühendislik Fakültesi, Makine Mühendisliği Bölümü, 16059, Bursa, Türkiye
}

(Alınış / Received: 26.04.2019, Kabul / Accepted: 17.11.2019, Online Yayınlanma / Published Online: 20.04.2020)

Anahtar Kelimeler Amfibik robot,

Titreşim,

İlerleme,

Elastik
Özet: Bu çalışma, robotik uygulamaları için, titreșime dayalı olarak hem karada hem de su üzerinde hareket edebilen, yenilikçi bir ilerleme mekanizmasını tanıtmaktadır. İlerleme mekanizması, su üzerinde batmadan durmasını sağlayan düşük yoğunluklu dikey kanat profiline sahip iki ayaktan ve U şeklinde yay çeliğinden üretilmiş elastik bir çubuktan oluşmaktadır. U şekilli çubuğun ortasına yerleştirilen basit bir sarkaç vasıtası ile sistem titreşime zorlanarak ilerleme gerçekleştirilmektedir. Su içerisinde dikey konumlandırılmış ayaklar salınım yaptıkça ön ve arka yüzeyler arasında oluşan basınç farkı ile robot ileri yönde hareket etmektedir. Karadaki hareketi ise elastik kirişin doğal titreşim modlarına bağlı olarak gerçekleşmektedir. Çalışmada farklı titreşim frekanslarının ilerleme hızına ve yer değiștirme maliyetine etkisi deneyler ile incelenmiş ve sonuçlar yorumlanmıştır. Buna ek olarak ön modelin yer değiștirme maliyeti (CoT) literatürdeki bazı robotlar ve canlılar ile karşılaştırılmıştır.

\section{Vibration Based Amphibious Locomotion Mechanism for Robotic Applications}

\section{Keywords}

Amphibious robot, Vibration, Locomotion, Elastic

\begin{abstract}
This work presents an innovative locomotion mechanism both on land and water surface based on vibration, for robotic applications. The locomotion mechanism consists of two legs with a low-density vertical wing profile that allows them to stand on water and a U-shaped elastic beam made of spring steel. The locomotion is generated by forcing the system to vibrate by means of a simple pendulum placed in the middle of the U-shaped bar. As the vertically positioned feet in the water oscillate, the robot moves in the forward direction with the pressure difference between the front and rear surfaces. The movement on the land is realized depending on the natural vibration modes of the elastic beam. In this work, the effect of different vibration frequencies on the locomotion velocity and the Cost of Transport (CoT) were investigated experimentally and the results were interpreted and discussed. In addition to these, the Cost of Transport of the preliminary model was compared with that of some robots and creatures in the literature.
\end{abstract}

\section{Giriş}

Tekerleğin icadı ile insanoğlu yeryüzündeki kara parçaları üzerinde ilerlemenin en verimli yolunu bulmuştur. Ancak, tekerlekli araçların ulaşamadığ farklı ortamlarda ilerleme ihtiyacı, bilim insanlarını canlıları taklit eden ilerleme mekanizmaları geliştirmeye zorlamaktadır. Zira dünya yüzeyinin çok küçük bir bölümü tekerlekli araçların ulaşımına uygun iken, bacak fizyolojisine bağlı olarak canlılar dünya yüzeyinin neredeyse tamamına ulaşabilmektedir. Günümüzde robotlar canlıları taklit eden yürüme, koşma, sıçrama ve yüzme gibi farklı yer değiștirme hareketlerini yapabilmektedirler. Ancak günümüz robotları bu yer değiștirme hareketlerini yüksek enerji tüketerek gerçekleştirebilirken, canlılar çok daha az kontrol girdisi ve enerji kullanarak daha karmaşık fakat kararlı yer değiștirme hareketleri yapabilmektedir. $\mathrm{Bu}$ nedenle, düşük enerji tüketim değerlerine sahip robotlar geliştirmek için hayvan hareketinin prensiplerini anlamak oldukça önemlidir. $\mathrm{Bu}$ konuda yapılan çalışmalar, özellikle hayvanların yürüyüş biçimlerine bağlı olarak yer değiștirme esnasında tükettikleri enerjiye odaklanmıştır [1-5]. Robotların ilerleme hareketleri üzerine yapılan çalışmalar esas olarak hayvanların hareketlerinin detaylı bir şekilde incelenmesi ve bu hareketlerin fiziksel modellerinin ortaya konulması șeklinde olmuştur [6]. Farklı ilerleme modelleri ve bu 
modellere ait robot örnekleri Calisti ve arkadaşları tarafından ayrıntılı bir şekilde incelenmiştir [7].

Pasif dinamik yürüme veya koşma hareketi yapabilen robotlar, diğerlerine göre daha az kontrol girdisine ihtiyaç duyarlar ve daha az enerji tüketimi ile hareketlerini gerçekleștirirler. $\mathrm{Bu}$ tür robotlar, herhangi bir hareket sağlayıcı motor veya kontrol birimi olmaksızın daha doğal yürüme yapabildikleri için insan ve hayvanların ilerlemeleri için kullanışlı bir model olarak gösterilebilirler [8-10]. Zıplayarak koşma hareketi hayvanlar tarafından özellikle yüksek hızlarda oldukça sık kullanılır. Hayvanlar ayrıca hareket kabiliyetlerini arttırabilmek için vücut uzuvlarının sertliğini ve şeklini değiștirmektedirler. Zıplayan robotlar üzerine yapılan çalışmalarda, özellikle ilerleme hareketi esnasinda sertlik ve șekil değiștirme yetenekleri üzerine araştırmalar yapılmıştır [11]. Zıplayan robotlar ile ilgili ilk araştırmalar 1980 'lerde MIT Bacak Laboratuvarı'nda (Leg Laboratory) yapılmıştır [12]. Bu çalışmalar sonucunda iki ve üç boyutlu hareketler yapabilen robot mekanizmaları geliştirilmiş, ancak bu mekanizmalar karmaşık yapıları ve aşırı enerji tüketim değerleri nedeniyle kendilerine kullanım alanı bulamamıștır. Buna karşın, uygun şekilde tasarlanmış elastik uzuvlu mekanizmalar, doğal titreşim davranışları manipüle edilerek daha düşük yer değiștirme maliyetine sahip bacaklı robotların geliştirilmesine imkân sağlamaktadır [13-14].

Robotlarda elastik uzuv kullanımı enerji verimliliği beraberinde bir dizi kontrol güçlüğü problemi getirmektedir. $\mathrm{Bu}$ güçlük elastik uzuvların doğal frekansı ile robotun periyodik ilerleme hareketinin frekansları örtüştürülerek giderilebilmektedir. Reis ve arkadaşları doğal titreşim modlarını kontrol girdisi olarak kullanarak yürüme, koşma, sürünme, ziplama hareketlerinin her birini gerçekleştirebilen ve oldukça düşük enerji tüketimine sahip elastik bir ilerleme mekanizması geliştirilmiştir [15-17]. Son yıllarda elastik uzuvlu pek çok robotik sistem geliştirilmiştir. Örneğin Bhatti ve arkadaşları tek ayaklı bir hidrolik robot için sıçrama yüksekliği, adım uzunluğu ve dolayısı ile uçuş süresini değiştirebilecek basit ama etkili bir kontrol ünitesi geliştirmiştir [18].

Mikro boyutlarda hem karada ve hem de suda ilerleyebilme özelliğine sahip robotlar oldukça popüler bir araştırma alanı olarak ortaya çıkmıştır. Amfibik özelliğe sahip ve hacimleri birkaç santimetre küp civarında olan bu robotlar daha çok çevre ve tıp alanlarında uygulama potansiyeline sahiptir. Bu robotlar suyun kaldırma kuvvetinin yanında yüzey gerilimini kullanarak ta su yüzeyinde hareket edebilmektedir. Tahrik sistemi piezo-elektrik malzeme kullanılarak yapılan amfibik mikro robotlar, piezo-mikro robotlar olarak isimlendirmektedir [19]. Tahrik sisteminin oluşturduğu titreşim ile, düz sert zeminlerde ve su yüzeyinde ilerleyebilen piezo-mikro robotlar, yüksek enerji verimine sahiptirler. Piezoelektrik sistemde elektrik enerjisinin yaklaşı $\% 90^{\prime} 1$ mekanik enerjiye dönüștürülebilmektedir [20]. Yakın zamanda, karada ve su üzerinde yürüyebilen ve bu yüzeyler arasındaki geçişi sağlayabilen dört ayaklı piezo-amfibik mikro robotlar geliştirilmiştir [21]. Bu amfibik mikro robotlar, ileriye doğru yüzmek ve dönebilmek için ayaklarının üzerine yerleştirilmiş pasif kanatları kullanmaktadır. Bu robotların diğer bir özelliği, ayaklarında bulunan elektro ıslanma sistemi vasitasıyla su üzerinde iken kontrollü bir dalış yaparak suyun altında inebilmeleri ve suyun içerisinde de ilerleyebilmeleridir. Ancak mikrorobotlar hafif olmaları nedeni ile oldukça sınırlı uygulama alanına sahiptirler. Bu çalışmalara paralel olarak, esas amacı mikro robotları görev alanına taşımak olan, yük taşıma kapasitesine sahip, daha büyük küresel amfibik robotlar da geliştirilmiştir [22]. Bu robotlar, iki çeyrek küresel kabuk ve plastik bir dairesel plakadan oluşan yarım küre biçimindeki amfibik robotlardır. Güncel çalışmalarda bu yapının hız performansını eğimli ve nispeten pürüzsüz yüzeylerde arttırmak amacı ile küresel robotun her ayağına pasif bir tekerlek takılarak paten-kayma hareketi yapması sağlanmıştır [23]. Son olarak bir su jeti eklenerek su altında ileriye itilmesi ve yönlendirilmesi sağlanan bu karma yapı, bir hibrit amfibik küresel robot halini almıștır [24].

Son zamanlarda dikkatleri üzerine çeken amfibik robotlar; altı bacaklı bir amfibik robot olan AmphiHex-II [25] ve bir vatoz gibi silikon yüzgeçlerini kullanarak hareket edebilen Velox' dur [26]. AmphiHex-II, farklı ortamlara adaptasyon sağlayabilmek için tasarlanmış ayarlanabilir ayak sertlikleri ile yüksek ilerleme performansına sahiptir. Velox ise, esnek yapıdaki dalgalı tahrik sistemi ile buzlu ya da karlı zeminde bile rahatlıkla ilerleyebilmekte ve aynı zamanda yüzgeçleri sayesinde etkin bir yüzme performansı göstermektedir.

Amfibik robotların birçoğunun hareket ve ilerleme mekanizmaları, canlıların hareketlerinden ilham alınarak geliştirilmiştir. Amfibik hayvanların sinir sistemleri incelenmiş ve sinir sistemleri merkezi model jeneratörü ile taklit edilmiştir. Bu şekilde yürüme, solunum ve yüzme gibi hareket modellerini kontrol edebilen bir robot hareket kontrol sistemi geliştirilmiş ve çok ayaklı bir amfibik robota uygulanmıştır [27]. Bunun yanında, amfibik kaplumbağalardan ilham alınarak, amfibik küresel bir robot geliştirilmiş [28] ve bu robot yapısı üzerine yukarıda belirtilen geliştirmeler [22-24] yapılarak, robotun hareket ve ilerleme performansı arttırılmıştır. Suyun üzerinde koşabilme yeteneği ile tanınan basilisk kertenkelesinden ilham alınarak tasarlanan, altı pedallı amfibik robot [29], suda yürüyebilen ve yüzebilen bir tür kuyruklu kurbağa cinsi semenderden ilham alınarak tasarlanan, dört bacaklı Salamandra robotu [30] ve son olarak, hamamböceğinden ilham alınarak tasarlanan, karma ilerleme mekanizmasına sahip altı bacaklı amfibik robot (AmphiHex-I) [31] doğayı taklit eden robot örneklerinin en bilinenleridir. 
$\mathrm{Bu}$ çalışmada, basit bir sarkaç tarafından titreşime zorlanan elastik bir mekanizmanın karadaki ve su üzerindeki ilerleme hareketi incelenmektedir. İlerlemeye etki eden tasarım değișkenlerini ve etkilerini belirlemek için kara ve su için iki farklı fiziksel model geliştirilmiştir. Karasal ilerleme modelinde, robotun omurga ile bacakları birbirlerine elastik dönme yayları ile bağlı olup, bacaklardaki boylamasına titreşimler doğrusal yaylar ile modellenmiştir. Mekanizmanın yayılı kütlesi, üç adet noktasal kütleye indirgenmiștir. Gövdenin merkezine yerleştirilen sarkacın salınım frekansı, bu yayların doğal frekanslarına ayarlandığında robotun çok düşük enerji tüketim değeri ile oldukça kararlı bir ilerleme hareketi ortaya koyduğu görülmüştür. Bu mekanizmanın kendi kendisini organize ederek gerçekleştirdiği ilerleme, herhangi bir merkezi otoriteye, algısal geri bildirime veya planlanmıș bir harekete neden olan harici bir elemana ihtiyaç duymamaktadır [16].

Sucul ilerleme modelinde ise, robot su üzerinde rijit bir cisim gibi davranmakta ve kayda değer bir şekil değişimi ve dönme hareketi yapmamaktadır. Bu sayede robot gövdesinin tamamı bir noktasal kütle, sarkaç ise bu kütle etrafında salınım yapan ikinci bir noktasal kütle olarak modellenebilmektedir. Omurganın merkezine yerleştirilmiş sarkaç harekete geçirildiğinde, robot gövdesi ile birlikte kanat şeklindeki ayaklar su içerisinde dikey yönde salınım hareketi yapmaktadır. $\mathrm{Bu}$ hareket nedeniyle ön ve arka yüzeyler arasında oluşan basınç farkı ve sarkacın oluşturduğu merkezkaç kuvvetinin etkisiyle elastik mekanizma su üzerinde planlanan yönde ilerleme hareketi yapabilmektedir. Bu sayede aynı mekanizmanın hem karada hem de su üzerinde ilerleyebilmesi sağlanarak, robotik uygulamalar için bacaklı amfibik bir ilerleme mekanizması geliştirilmiştir. Mekanizma katı yüzeylerde elastik gövdenin farklı rezonans modları tahrik edilerek yürüme, koşma, zıplama ve sürünme benzeri karasal ilerleme hareketleri yapabilirken, geliștirilen ayak yapısı sayesinde su üzerinde de ilerleyebilmektedir.

Çalışmanın ilk bölümünde mekanizmanın genel tanıtımı, karasal ve sucul ilerleme modelleri, tasarım parametreleri ile mekanizmanın karasal ilerlemesinde etkili olan rezonans frekansları ve sucul hareketi idare eden denklemler verilmektedir. Sonrasında deney sonuçları verilmekte ve bu sonuçların değerlendirilmesi yapılmaktadır. Sonuç bölümünde genel değerlendirmeler ve mevcut çalışmanın sonuçlarından yola çıkarak gelecekte yapılabilecek çalışmalardan bahsedilmektedir.

\section{Materyal ve Metot}

Amfibik ilerleme mekanizmasının temel ilerleme dinamiklerini karakterize edebilmek için karasal ve sucul ilerleme hareketleri için basitleştirilmiş iki farklı fiziksel model geliştirilmiştir. Bu sayede elastik mekanizmanın karada ve sudaki dinamik davranışına etki eden temel tasarım değişkenleri ve etkileri anlaşılabilmektedir. Mekanizma, basit bir mikro DC motor, batmaya karşı poliüretan köpükten yapılmıș kanat şeklindeki iki duba ayak ve U şekli verilerek bükülmüş elastik bir çubuktan oluşmaktadır. Yay çeliğinden üretilmiş, et kalınlığı $a=0.8 \mathrm{~mm}$ ve genişliği $b=2 \mathrm{~mm}$ lama kesite sahip $E$ elastisite modülü $200 \mathrm{GPa}$ olan elastik çubuk, robotun bacaklarını ve omurgasını oluşturmaktadır. Omurganın merkezine monte edilmiş mikro DC motora küçük bir sarkaç bağlanmıştır. Sarkaç, robotun tahrik sistemi olup, sarkacı tahrik eden mikro motor, $1 / 90$ çevrim oranına sahip plastik bir dişli kutusuna sahiptir. Robotun karada ve su yüzeyinde hareketini sağlayabilmek için çok düşük yoğunluklu malzemeden üretilmiş iki ayak tarafından desteklenmektedir. Yarım elips kesitine sahip poliüretan ayaklar $\% 50$ oranında suya batmak suretiyle robotun 11 gr' lık toplam $M$ kütlesini statik olarak tașımaktadır. Deneyler için geliştirilen amfibik ilerleme mekanizmasını fotoğrafı Şekil 1' de, boyutları ve kütleler Tablo 1' de verilmektedir.

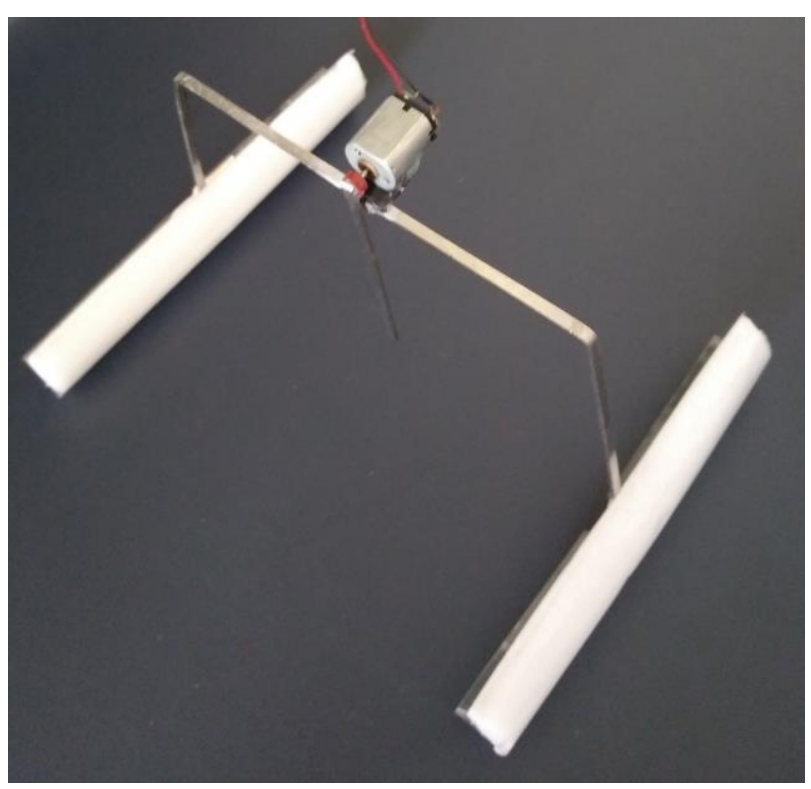

Şekil 1. Amfibik ilerleme mekanizmasının fotoğrafı

Tablo 1. Robot ön modelinin boyutları

\begin{tabular}{ll}
\hline Değişken & Boyut \\
\hline$m_{\text {motor }}$ & 3 gr \\
\hline$m_{f}, m_{h}$ & 0,4 gr $-0,4 \mathrm{gr}$ \\
\hline$m_{\mathrm{R}}$ & $0,7 \mathrm{gr}$ \\
\hline$M$ & $11 \mathrm{gr}$ \\
\hline$L_{v}$ & $75 \mathrm{~mm}$ \\
\hline$L_{h}$ & $85 \mathrm{~mm}$ \\
\hline$R$ & $25 \mathrm{~mm}$ \\
\hline$E$ & $200 \mathrm{GPa}$ \\
\hline$r_{1}$ & $10 \mathrm{~mm}$ \\
\hline$r_{2}$ & $7 \mathrm{~mm}$ \\
\hline$l_{p}$ & $90 \mathrm{~mm}$ \\
\hline$a$ & $0.8 \mathrm{~mm}$ \\
\hline$b$ & $2 \mathrm{~mm}$ \\
\hline
\end{tabular}




\subsection{Karasal ilerleme modeli}

Amfibik mekanizmanın karada ilerlemesinin sistematik bir analizini yapabilmek ve karasal hareket için fiziksel bir model oluşturabilmek için şu varsayımlar yapılmıştır [16];

- Robotun davranışı sagital düzlemde analiz edilebilir ve ayakların her birinin zemin ile teması bir noktasal temas olarak değerlendirilebilir.

- Robotun omurgası ve bacakları birbirlerine elastik dönme yayları ve sönümleyiciler ile bağlı elemanlar olarak kabul edilebilir.

- Bacaklardaki boylamasına titreşim doğrusal yay ve sönümleyiciler ile modellenebilir.

- Omurga ve DC motorun kütleleri omurganın merkezinde birleşik bir nokta kütle olarak alınabilir.

- Bacakların kütleleri ihmal edilebilir ve ayakların her biri birer noktasal kütle olarak alınabilir.

- Titreşimi esnasında robotun gövde yapısında kalıcı şekil değişimlerin olmadığı kabul edilmektedir.

Bu varsayımlara dayanarak, karasal ilerleme hareketi için oluşturulan basitleștirilmiş fiziksel model, Şekil 2' de gösterilmektedir. Karasal model, yaysönümleyici elemanlar ile birbirine bağlı üç farklı yapıdan oluşmaktadır. Bu elemanların yayılı kütleleri Şekil 2' de gösterildiği gibi noktasal kütlelere indirgenmiştir. Bu noktasal kütlelerden ilki eyleyici ve omurga kütlelerini temsil eder ve omurganın merkezinde yer almaktadır $\left(m_{t o p}\right)$. Diğer iki kütle ise ön ve arka ayak kütlelerini temsil eden $m_{f}$ ve $m_{h}{ }^{\prime}$ dir. Omurganın uzunluğu $L_{h}$ ile, ön ve arka bacakların uzunlukları $L_{v}$ ile ve bacak ile omurgaya dik olan çizgi arasındaki açlar $\theta_{f}$ ve $\theta_{h}$ ile ifade edilmektedir. Elastik çubuğun herhangi bir sıkışma veya uzama etkisinde kalmadığı durumda, simetrik haldeki robotun bacaklarının doğal uzunlukları ile açılar $L_{0}$ ve $\theta_{0}$ ile gösterilir. Omurga ve bacaklar, burulma sertliği $k_{\theta}$ ve sönümleme katsayısı $d_{\theta}$ olan elastik dönme yayları ile bağlanır. Robotun bacakları, sertliği $k_{L}$ ve sönümleme katsayısı $d_{L}$ olan doğrusal yaylar olarak modellenmiştir. Omurganın merkezine sabitlenmiş kütlesi $m_{\text {motor }}$ ile verilen motor, ucuna $m_{R}$ kütlesi bağlanmış $R$ uzunluğundaki bir çubuğu $\omega$ açısal hızı ile döndürmekte olup, çubuğun omurga ile yaptığı açı $\beta$ ile verilmektedir. Sonuç olarak, bu basit model 13 mekanik tasarım parametresinden $\left(k_{\theta}, d_{\theta}, k_{L}, d_{L}\right.$, $\theta_{f 0}, \theta_{h 0}, L_{h}, L_{v 0}, m_{f}, m_{h}, m_{t o p}, R$ ve $\left.m_{\mathrm{R}}\right)$, bir kontrol parametresinden $(\omega)$ ve 16 durum değişkeninden $\left(x_{f}\right.$, $y_{f}, x_{h}, y_{h}, L_{v}, \theta_{f}, \theta_{h}, \beta$ ve bunların zamana göre birinci türevleri) oluşmaktadır. Burada $x_{f}$ ve $y_{f}$ ön ayakların yatay ve düşey konumlarını, $x_{h}$ ve $y_{h}$ arka ayakların yatay ve düşey konumlarını göstermektedir.

Robotun karasal hareketi rezonans frekanslarına bağlı olarak ortaya çıkan yüksek genlikteki şekil değişimleri ile oluşmaktadır. İki boyutlu bu yapıda, ayakların çarpılması ve boylamasına sıkışıp uzaması şeklinde iki baskın titreşim hareketi ortaya çıkmaktadır ve basit fiziksel model bu iki harekete izin verecek şekilde özel olarak seçilmiştir. İlk titreşim modu daha düşük bir salınım frekansında $\left(\omega_{\theta}\right)$ ortaya çıkmaktadır ve robotun ters sarkaç hareketi sonucu robot yürüme hareketi yapmaktadır. İkinci titreşim modu daha yüksek bir salınım frekansında $\left(\omega_{L}\right)$ gerçekleşir ve bacakların boyuna titreşimleri sonucu robot zıplayarak ilerler. Farklı gövde oranları için ara frekans değerlerinde robot sürünerek ve koşarak ilerleme yapabilmektedir [16].

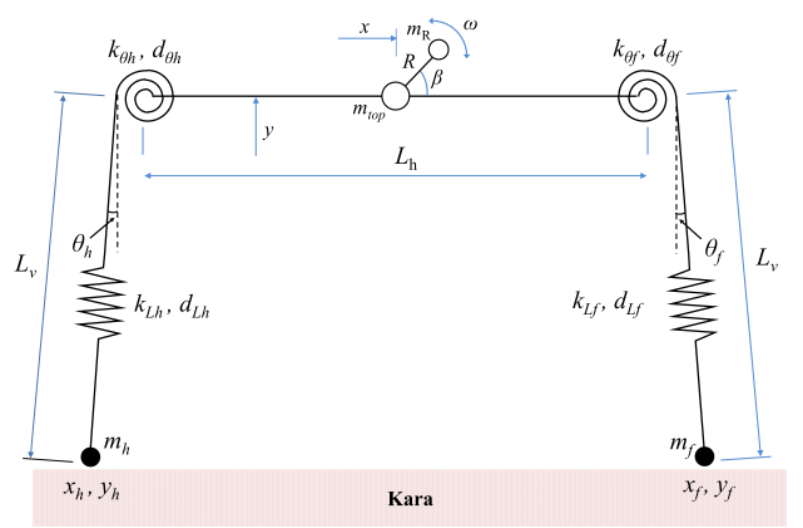

Şekil 2. Basitleştirilmiş karasal ilerleme modeli [16]

Robot ön modelinin $\omega_{\theta}$ ve $\omega_{L}$ rezonans frekansları hem deneysel hem de analitik olarak elde edilmiştir. Sarkacın açısal hızı elastik gövdenin doğal frekanslarına ayarlanarak serbest titreşim modları görsel olarak kolayca belirlenebilmektedir. $\mathrm{Bu}$ değerler doğrusal ve dönme yaylarının sertlik değerleri ölçülerek te hesaplanabilmektedir. Burada, kullanılan elastik yay çeliğinde sönüm katsayısının çok küçük olduğu, her iki bacağın başlangıç boylarının $L_{0}$, başlangıç açılarının ise sıfıra eşit olduğu varsayılmaktadır ( $\left.\theta_{0}=0(\mathrm{rad})\right)$.

Basitleştirilmiş modelde çarpılma (torsiyonel) rezonans frekansı için en basit analitik çözümlerden biri, elastik robotu birbirine dönme yayları ile bağlı paralel çubuk mekanizması olarak kabul edilerek hesaplanabilir $\left(\theta_{f}=\theta_{h}=\theta\right.$ ve $\left.L_{v}=L\right)$. Bu durumda, Uşeklindeki elastik çubuğun çarpılma rezonans frekansı $\left(\omega_{\theta}\right)$

$$
\omega_{\theta}=\sqrt{\frac{2 k_{\theta}-m_{\text {top }} g L}{m_{\text {top }} L^{2}}}
$$

ve elastik kirişin boyuna rezonans frekansı $\left(\omega_{L}\right)$

$$
\omega_{L}=\sqrt{\frac{2 k_{L}}{m_{t o p}}}
$$

olarak basitçe ifade edilebilir [16]. Burada $k_{\theta}$ ve $k_{L}$ sırası ile Şekil 2' de gösterildiği gibi omurga ile bacaklar arasındaki birleşme noktasında çubuğun burulma sertliğini $(k \theta)$ ve bacakların boyuna sertliğini $\left(k_{L}\right)$ temsil etmektedir. 
Robotu titreşime zorlayarak ilerlemesini sağlayan tahrik sistemi herhangi bir algisal geri bildirime sahip olmayan basit bir DC motor ve sarkaçtan ibarettir. Sarkacın açısal hızı, motora uygulanan gerilim ile değiştirilebilir. Dönen kütlenin açısal hızının sabit olduğu varsayılarak $\mathrm{F}(\mathrm{t})$ merkezcil kuvveti, açısal hız $\omega$, dönen kütle $m_{R}$ ve dönme yarıçapı $R$ cinsinden aşağıdaki gibi ifade edilebilir:

$$
F(t)=m_{R} \omega^{2} R
$$

$\mathrm{Bu}$ ifadeden, robotun titreşiminde açısal hızın yanında dönen kütle ve dönme yarıçapı gibi diğer tasarım parametrelerinin de etkili olduğunu anlaşılmaktadır.

\subsection{Sucul ilerleme modeli}

Amfibik mekanizmanın su üzerindeki ilerlemesini ifade eden, basit bir fiziksel model kurmak için aşağıdaki kabuller yapılmaktadır;

- Robot su içerisinde rijit bir cisim gibi davranmakta, elastik gövde kayda değer bir şekil değişimi göstermemektedir.

- Robotun su içerisinde dönme hareketi yapmadığ $\mathrm{x}$ ve y eksenlerinde ötelenme hareketi yaptığı kabul edilmektedir ki, deneyler bu kabulü doğrulamaktadır. Böylece robot gövdesinin tamamı bir noktasal kütleye, sarkaç ise ana gövdeye bağlı ikinci bir noktasal kütleye indirgenebilmektedir.

$\mathrm{Bu}$ varsayımlara dayanarak oluşturulan robotun fiziksel modeli Şekil 3' de gösterilmektedir. Sucul ilerleme modelinde robot rijit cisim olarak ele alınmakta olup, robotun gövdesinin tamamı bir noktasal kütle, $m_{\text {top }}$, sarkaç ikinci bir noktasal kütle $m_{R}$ olarak temsil edilmektedir. Omurga uzunluğu $L_{h}$, rijit bacakların uzunlukları $L_{v}$, ayakların uzunlukları $L_{p}$, eliptik ayak kesit yüzeyinin düşey ve yatay yarıçapları sırası ile $r_{1}$ ve $r_{2}$ ile ifade edilmektedir. Ön ve arka ayakların kütleleri $m_{f}$ ve $m_{h}$, hacimleri ise $V_{f}$ ve $V_{h}$ ile verilmektedir. Özet olarak, sucul ilerleme modeli 12 mekanik tasarım parametresinden $\left(L_{h}, L_{v}, L_{p}, r_{1}, r_{2}, \mathrm{~V}_{f}\right.$, $\mathrm{V}_{h}, m_{f}, m_{h}, m_{\text {top }}, R$ ve $m_{R}$ ) oluşmaktadır.

Yukarıda tanımlanan ve Şekil 4'de gösterilen iki noktasal A ve B kütleleri ele alınarak, su üzerinde dönmeden ötelenen robotun ve sarkacın için ivme ifadeleri aşağıdaki gibi elde edilir.

$$
\begin{gathered}
a_{\mathrm{A}}=\ddot{x} \mathrm{i}+\ddot{y} \mathrm{j} \\
a_{B}=\left[\ddot{x}-R \omega^{2} \cos \beta\right] i+\left[\ddot{y}-R \omega^{2} \sin \beta\right] j, \\
\dot{\beta}=\omega, \ddot{\beta}=0
\end{gathered}
$$

Şekil 4' de gösterilen iki noktasal kütlenin serbest cisim diyagramları yardımı ve 4-6 nolu denklemlerde verilen ivme ifadelerinin kullanılması ile, sucul ilerleme için hareket denklemleri (7-13 nolu denklemler) elde edilmiştir. Bu denklemler bir adet bağımsız değişken (zaman; $t$ ), bir adet kontrol parametresi $(\dot{\beta}=\omega)$, altı adet bağımlı değişken $(x, y$, $T, F_{w}, D_{w}$, ? ?) ve türevlerini ihtiva etmektedir.

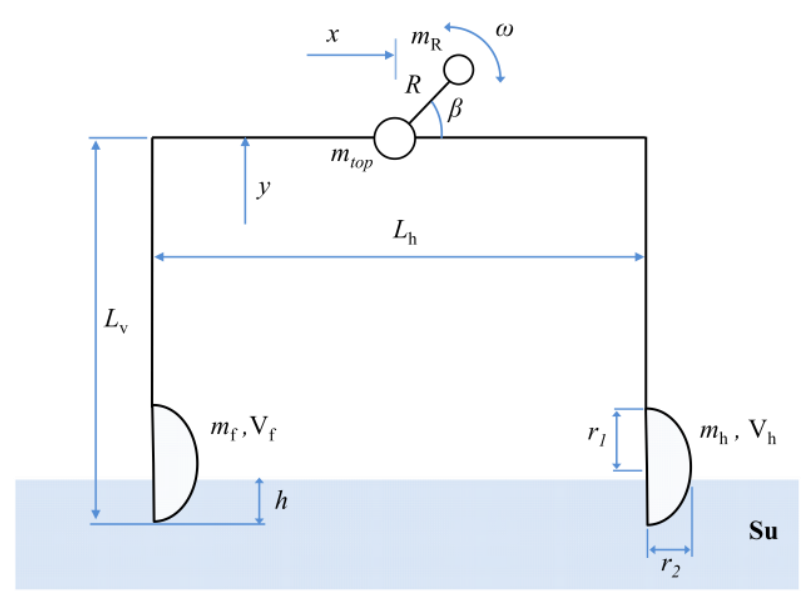

Şekil 3. Basitleştirilmiş sucul ilerleme modeli

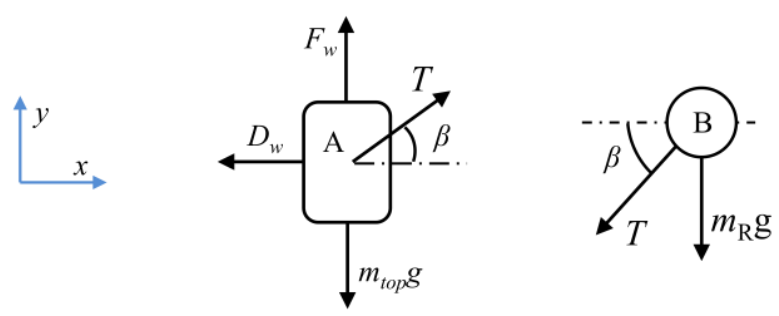

Şekil 4. Sucul ilerleme modeli için serbest cisim diyagramları

$$
\begin{gathered}
D_{w}+T \cos \beta=m_{t o p} \ddot{x} \\
F_{W}+T \sin \beta=m_{t o p} \ddot{y} \\
-T \cos \beta=m_{R}\left[\ddot{x}-R \omega^{2} \cos \beta\right] \\
-T \sin \beta-m_{R} g=m_{R}\left[\ddot{y}-R \omega^{2} \sin \beta\right] \\
\beta=\beta_{0}+\omega t \\
F_{w}=k \cdot y^{n} \\
D_{w}=d_{f} \cdot \frac{|\dot{x}|^{m}}{2} \cdot \frac{|\dot{x}|}{\dot{x}} \cdot(-1) \cdot\left[\frac{|\dot{x}|}{\dot{x}}+1\right]+d_{h} \cdot \frac{|\dot{x}|^{m}}{2} \cdot \frac{|\dot{x}|}{\dot{x}} \cdot\left[\frac{|\dot{x}|}{\dot{x}}-1\right]
\end{gathered}
$$

Burada, $\ddot{x}$ ve $\ddot{y}$ ivmenin yatay ve düşey bileşenlerini, $g$ yer çekim ivmesini, $\beta_{0}$ sarkacın başlangıçta yer ile yaptığı açıyı, $T$ sarkaç kuvvetini, $F_{w}$ suyun kaldırma kuvvetini, $D_{w}$, ise suyun direncini ifade etmektedir.

\section{Bulgular}

Amfibik ilerleme mekanizması, titreşime dayalı hareket eden karasal bir ilerleme mekanizması [1517] geliştirilerek, su üzerinde de hareketini sağlamak sureti ile elde edilmiştir. Bu amaçla robotun boyutları yeniden belirlenerek, yarı eliptik bir kanat profilli ayaklara sahip bir ön model üretilmiş ve deneylerde kullanılmıştır. Yapılan ölçümler esnasında, sarkacın açısal hızı DC motora uygulanan $V$ gerilimi ile kontrol edilmiş ve aynı zamanda motor tarafından çekilen $I$ 
akımı, enerji tüketimini hesaplamak için kaydedilmiștir. Robotun hareketi hem karada hem de su dolu 70x150 cm boyunda bir akvaryum içerisinde hızlı kamera ile kayıt edilmiş ve sarkacın frekansı hızlı kamera kayıtlarından ölçülmüștür. DC motor gerilimi, 1.2 Volt ile 2.1 Volt aralığında 0.1 Volt adımlarla artırılarak ölçümler yapılmıştır.

Şekil 5' de robotun karasal ve sucul $v$ ilerleme hızlarının sarkacın açısal hızı ile değişimi görülmektedir. Robot karasal zeminde $38 \mathrm{rad} / \mathrm{s}$ ve su üzerinde ise $65 \mathrm{rad} / \mathrm{s}$ açısal hız değerinde en yüksek yer değiştirme hızına ulaşmaktadır. Deneysel verilerin alındığı frekans değerleri dışında kalan bölgelerde ise robot kayda değer bir yer değiştirme hareketi yapmamaktadır.

Şekil 6' da robotun karasal ve sucul yer değiştirme maliyetinin (Cost of Transport- CoT) sarkacın açısal hızı ile değişimi görülmektedir. Benzer şekilde robot en düșük yer değiștirme enerjisi değerlerine karasal zeminde $31 \mathrm{rad} / \mathrm{s}$ ve su üzerinde ise $16 \mathrm{rad} / \mathrm{s}$ açısal hız değerlerinde ulaşmaktadır. Burada, ilerleme hızındaki çok küçük artış ile birlikte, DC motora uygulanan gerilimin de yakın oranlarda artması belli bir aralıkta birim kütle başına enerji tüketimini sabit tutmaktadır.

Şekil 7' de çeşitli mekanizmalar ve biyolojik organizmalar için vücut kütlesine göre taşıma maliyetinin değişimi gösterilmektedir. Tucker diyagramı [32] olarak bilinen bu grafikte çeşitli canlılar ve makinelerin birim kütle başına yer değiștirme maliyetleri boyutsuz birer sayı ile gösterilmektedir. Tüm değerlerin tek bir eğri üzerinde gösterilebilmesi logaritmik bir eğri kullanımını zorunlu kılmaktadır. Diyagramdaki kırmızı yıldız sembolü çalışmada tanıtılan mekanizmanın karasal zemindeki ilerleme maliyetini, mavi yıldız sembolü ise su üzerindeki ilerleme maliyetini göstermektedir. Grafikten anlaşılacağı üzere su canlıları yer değiștirmek için en az enerjiye ihtiyaç duyan türdür. Buna karşıllk mevcut ilerleme mekanizmasının enerji tüketim değeri oldukça yüksek gözükmektedir. Ancak eğride dikkat edilmesi gereken bir diğer nokta, canlı organizmalar dâhil olmak üzere, tüm türlerde kütle azaldıkça birim kütle başına yer değiştirme enerjisi ihtiyacının hızla arttı̆̆ıdır. Mevcut robotun daha büyük kütleli versiyonlarında birim kütle başına yer değiştirme enerjisi ihtiyacı logaritmik olarak azalacak ve literatürdeki robotların seviyesine inecektir.

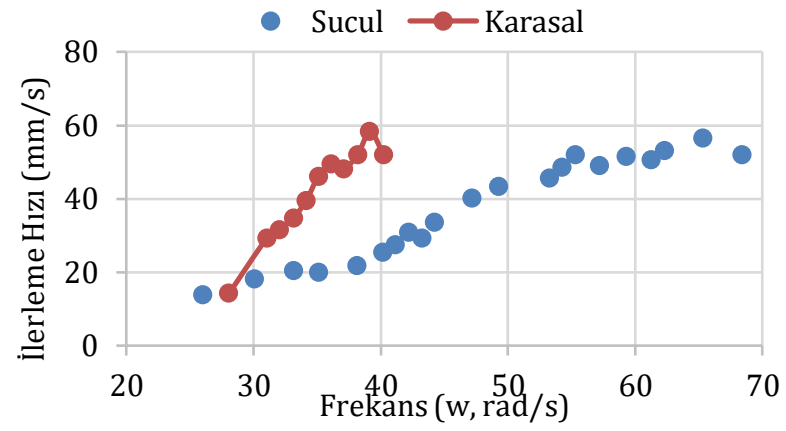

Şekil 5. Karasal ve sucul ilerleme hızlarının sarkacın açısal hızı ile değişimi

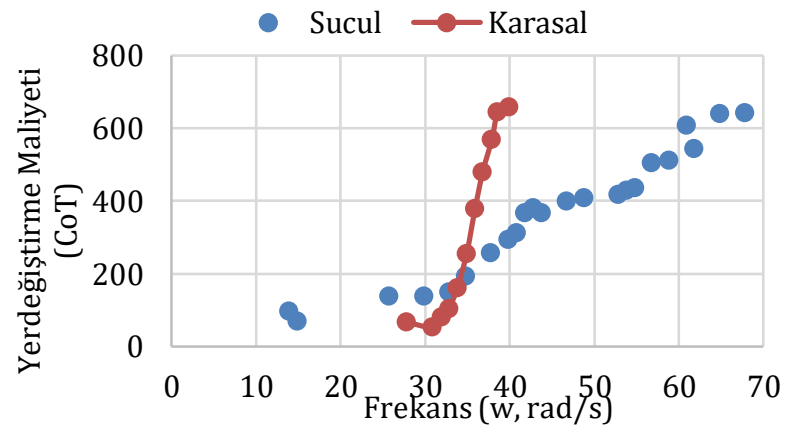

Şekil 6. Karasal ve sucul yer değiștirme maliyetlerinin (CoT) sarkacın açısal hızı ile değişimi

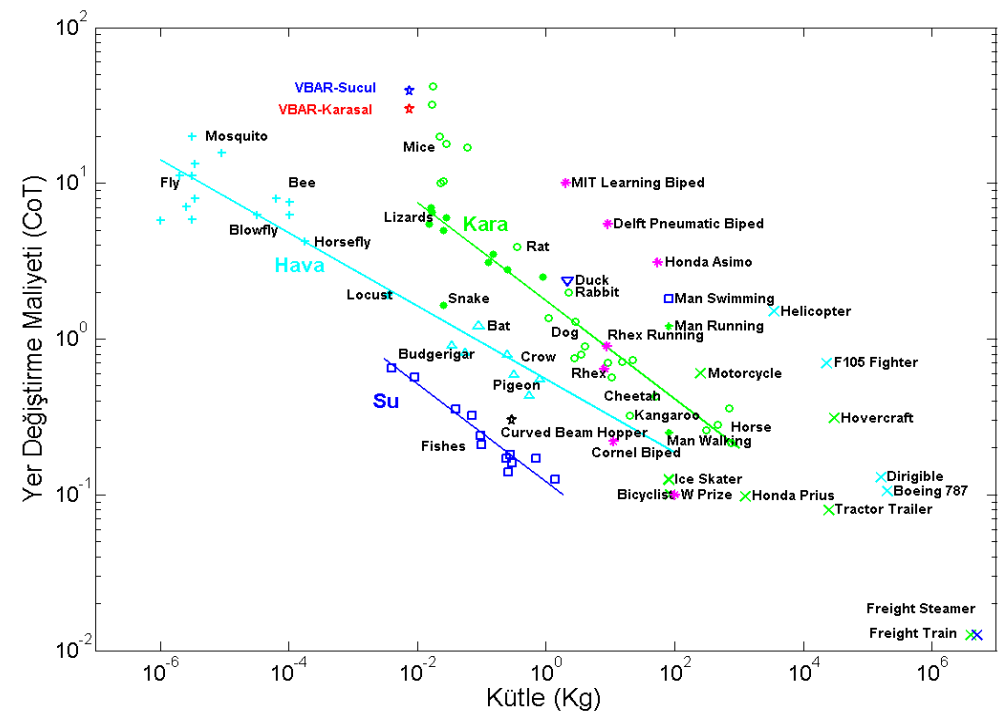

Şekil 7. Çeşitli mekanizmalar ve biyolojik organizmalar için vücut kütlesine göre taşıma maliyeti (Tucker diyagramı [32]). Mavi ve kırmızı yıldız sembolleri, çalışmada tanıtılan mekanizmanın karasal ve sucul ilerlemeleri için diyagramdaki yerlerini göstermektedir. 


\section{Tartışma ve Sonuç}

Bu çalışmada, titreşime zorlanan bir basit bir elastik çubuğun uygun geometri ve ayak yapısı ile bir amfibik ilerleme mekanizmass olarak kullanılabileceği gösterilmiştir. Daha önceki çalışmalarımızda aynı prensipler kullanılarak karada ilerleyen, oldukça düşük enerji tüketimi olan ve farklı salınım frekanslarında farklı ilerleme şekilleri gösteren mekanizmalar tanıtılmıştı. Bacaklı robotlar yüksek enerji tüketim değerleri nedeniyle pratikte çok kullanışlı değillerdir. Ancak elastik elemanların ve farklı ilerleme yöntemlerinin geliştirilmesi ile birlikte bu tüketim değerleri biyolojik organizmaların seviyesine yaklaşabilmektedir.

$\mathrm{Bu}$ çalışmanın sonuçlarından faydalanarak, ilerleyen dönemlerde suda daha hızlı ilerlemeyi sağlayacak bir ayak yapısının geliştirilmesi hedeflenmektedir. Bu sayede yer değiştirme maliyetinin düşürülmesi ve su canlılarının ilerleme maliyetine daha yakın değerlere ulaşılması amaçlanmaktadır. Geliştirilecek ayak yapısı aynı zamanda robotun karadan-suya ve sudan karaya kolaylıkla geçişini sağlayabilecek şekilde olmalıdır. Her ne kadar mevcut ayak yapısı ile bu geçiş sağlanmışsa da mekanizmanın farklı yüzeyler arasındaki geçiş performansını arttırmaya yönelik çalışmalar devam etmektedir. Mevcut ilerleme mekanizması hem karada hem de suda ilerleyebilme yeteneğinin yanı sıra ölçeklenebilirliği sayesinde çok küçük ve çok büyük boyutlarda üretilebilme özelliğine sahiptir. Öyle ki, hidro-statik yüzey gerilimlerinin yardımı ile su yüzeyinde kalabilecek kadar küçük boyutlu robotların üretimi mümkün olmaktadır. Ancak suya batmayan bir robotun titreşim ile ilerlemesi için yine farklı bir ayak yapısının geliştirilmesini gerekmektedir. Bunların yanında, miligram mertebesinde kütleye sahip bir robota elektrik enerjisinin iletilmesi de oldukça problemli ve zor bir iştir. Zira, çok ince kablolar kullanılmasına rağmen kablolarda oluşan gerilmeler robotun hareketini etkilemekte ve kısıtlamaktadır. $\mathrm{Bu}$ problem ayrıca üzerinde çalışılması gereken konulardan bir tanesi olarak durmaktadır.

\section{Kaynakça}

[1] Kar, D.C., Kurien, I.K., Jayarajan, K. 2003. Gaits and energetics in terrestrial legged locomotion. Mechanism and Machine Theory, 38, 355-366.

[2] Armour, R., Paskins, K., Bowyer, A., Vincent, J., Megill, W. 2007. Jumping robots: a biomimetic solution to locomotion across rough terrain. Bioinspiration \& Biomimetics, 2, 565-582.

[3] Zhang, Z., Chen, D., Chen, K., Chen, H. 2016. Analysis and comparison of two jumping leg models for bioinspired locust robot. Journal of Bionic Engineering, 13, 558-571.

[4] Hanan, U. B., Weiss, A., Zaitsev, V. 2018. Jumping efficiency of small creatures and its applicability in robotics. Procedia Manufacturing, 21, 243250.

[5] Kelasidi, E., Jesmani, M., Pettersen, K. Y., Gravdahl, J. T. 2018. Locomotion efficiency optimization of biologically inspired snake robots. Applied Science, 8, 1-23.

[6] Alexander, R. N. 2006. Principles of animal locomotion. Princeton University Press. Princeton, NJ, 384s

[7] Calisti, M., Picardi, G., Laschi, C. 2017. Fundamentals of soft robot locomotion. Journal of Royal Society Interface, 14, 1-16.

[8] McGeer, T. 1990. Passive dynamic walking. The International Journal of Robotics Research, 9(2), 62-82.

[9] Collins, S., Ruina, A., Tedrake, R., Wisse, M. 2005. Efficient bipedal robots based on passive dynamic walkers. Science, 307, 1082-1085.

[10] Owaki, D., Koyama, M., Yamaguchi, S., Kubo, S., Ishiguro, A. 2010. A two-dimensional passive dynamic running biped with knees. IEEE International Conference on Robotics and Automation, Mayıs 3-8, Alaska, 5237-5242.

[11] Kühnel, D.T., Helps, T., Rossiter, J. 2016. Kinematic Analysis of VibroBot: A Soft, Hopping Robot with Stiffness and Shape-Changing Abilities. Frontiers in Robotics AI, 3(60), 1-11.

[12] Raibert, M.H. $1986 . \quad$ Legged robots. Communications of the ACM, 29, 499-514.

[13] Yu, X., Iida F. 2014. Minimalistic models of an energy-efficient vertical-hopping robot. IEEE Transactions and Industrial Electronics, 61(2), 1053-1062

[14] Geyer, H., Blickhan, R., Seyfarth, A. 2005. Springmass running: simple approximate solution and application. Journal of Theoretical Biology, 232, 315-328.

[15] Reis, M., Iida, F. 2011. Vibration based underactuated bounding mechanism IEEE/ASME International Conference on Advanced Intelligent Mechatronics, 892-897.

[16] Reis, M., Yu, X., Maheshwari, N., Iida, F. 2013. Morphological computation of multi-gaited robot locomotion based on free vibration. Artificial Life, 19, 97-114.

[17] Reis, M., Iida, F. 2014. An energy-efficient hopping robot based on free vibration of a curved beam. IEEE/ASME Trans. Mechatronics, $19,300-311$.

[18] Bhatti, J., Hale, M., Iravani. P., Plummer, A., Sahinkaya, N. 2017. Adaptive height controller for an agile hopping robot. Robotics and Autonomous Systems, 98, 126-134.

[19] Steltz, E., Seeman, M., Avadhanula, S., Fearing, R. S. 2006. Power Electronics Design Choice for 
Piezoelectric Microrobots. IEEE/RSJ International Conference on Intelligent Robots and Systems, 9-15 Ekim, Pekin, Çin, 1322-1328.

[20] Becker, F., Zimmermann, K., Volkova, T., Minchenya, V.T. 2013. An Amphibious Vibrationdriven Microrobot with a Piezoelectric Actuator: 7. Regular and Chaotic Dynamics,18(1-2), 6374.

[21] Chen, Y., Doshi, N., Goldberg, B., Wang, H., Wood, R.J. 2018. Controllable water surface to underwater transition through electro wetting in a hybrid terrestrial aquatic microrobot. Nature Communications 9(2495), 1-11.

[22] Li, M., Guo, S., Hirata, H., Ishihara, H. 2015. Design and performance evaluation of an amphibious spherical robot. Robotics and Autonomous Systems, 64, 21-34.

[23] Li, M., Guo, S., Hirata, H., Ishihara, H. 2017. A roller-skating/walking mode-based amphibious robot. Robotics and Computer-Integrated Manufacturing, 44, 17-29.

[24] Xing, H., Guo, S., Shi, L., He, Y., Su, S., Chen, Z. Hou, $X$. 2018. Hybrid Locomotion Evaluation for a Novel Amphibious Spherical Robot. Applied Science, 8(156), 1- 24.

[25] Zhong, B., Zhang, S., Xu, M., Zhou, Y., Fang, T., Li, W. 2018. On a CPG-Based Hexapod Robot: AmphiHex-II With Variable Stiffness Legs. IEEE/ASME Transactions on Mechatronics, 23(2), 542-551
[26] Pliant Enerji Sistemleri, 2019. Velox tanitım sayfass. https://www.pliantenergy.com/home-1 (Erișim Tarihi: 07.02.2019).

[27] Matsuo, T., Yokoyama, T., Ueno, D., Ishii, K. 2008. Biomimetic Motion Control System Based on a CPG for an Amphibious Multi-Link Mobile Robot. Journal of Bionic Engineering Suppl., 91-97.

[28] Shi, L., Guo, S., Mao, S., Yue, C., Li, M., Asaka, K. 2013. Development of an Amphibious TurtleInspired Spherical Mother Robot. Journal of Bionic Engineering, 10, 446-455.

[29] Kim, H.G., Lee, D.G., Liu, Y., Jeong, K., Seo, T.W. Hexapedal Robotic Platform for Amphibious Locomotion on Ground and Water Surface. Journal of Bionic Engineering, 13, 39-47.

[30] Crespi, A., Karakasiliotis, K., Guignard, A., Ijspeert, A.J. 2013. Salamandra Robotica II: An Amphibious Robot to Study Salamander-Like Swimming and Walking Gaits. IEEE Transactions on Robotics, 29(2), 308-320.

[31] Zhang, S., Liang, X., Xu, L., Xu, M. 2013. Initial Development of a Novel Amphibious Robot with Transformable Fin-Leg Composite Propulsion Mechanisms. Journal of Bionic Engineering, 10, 434-445.

[32] Tucker, V.A. 1975. The Energetic Cost of Moving About: Walking and running are extremely inefficient forms of locomotion. Much greater efficiency is achieved by birds, fish and bicyclists. American Scientist, 63(4), 413-419. 